\title{
Temsirolimus Is Highly Effective as Third-Line Treatment in Chromophobe Renal Cell Cancer
}

\author{
Dimitrios Zardavas Alexander Meisel Panagiotis Samaras \\ Alexander Knuth Christoph Renner \\ Bernhard C. Pestalozzi Frank Stenner-Liewen \\ Department of Oncology, University Hospital Zürich, Zürich, Switzerland
}

\section{Key Words}

Temsirolimus · Chromophobe renal cell cancer · Liver metastases · Sunitinib · Sorafenib

\begin{abstract}
We report unexpectedly high efficacy of temsirolimus as third-line treatment in a patient with metastatic chromophobe renal cell carcinoma. After failure of two sequentially administered tyrosine kinase inhibitors, treatment with temsirolimus resulted in a prolonged partial remission of 14 months, and the response is still continuing. Up to now, no data from randomized clinical studies have been published addressing the question of efficacy of temsirolimus as third-line treatment after failure of tyrosine kinase inhibitors. The case presented here implies that temsirolimus could be a viable option for patients with metastatic chromophobe renal cell carcinoma.
\end{abstract}

\section{Case Report}

A 27-year-old female patient developed macrohematuria in January 2004. Imaging showed a large right renal mass without metastases. She underwent nephrectomy, and the histology revealed a renal cell carcinoma (RCC) of chromophobe type, eosinophilic variant. Maximum tumor diameter was $12 \mathrm{~cm}$, with extensive necrosis, grade IV according to Fuhrman's nuclear grading system. A single hilar lymph node was found to be infiltrated, resulting in stage $\mathrm{pT} 2 \mathrm{pN} 1 \mathrm{cM} 0$. Neither the renal vein nor the adrenal gland was infiltrated.

In August 2007, a routine follow-up ultrasound revealed multiple liver lesions. Fine needle aspiration confirmed the diagnosis of liver metastases of chromophobe RCC. A CT scan showed multiple bilateral pulmonary as well as diffuse liver metastases. Treatment with sunitinib $50 \mathrm{mg}$ on a 4 weeks on/2 weeks off schedule was initiated, resulting in stable disease. However, the doses had to be reduced due to grade 3 palmar and plantar toxicity.

At the end of March 2009, after 20 months of treatment, an MRI showed progressive liver disease as well as local recurrence and mesenteric lymph node metastases. Sorafenib was started as a second-line treatment. The initial dose of $800 \mathrm{mg}$ daily had to be reduced to $600 \mathrm{mg}$ due to a hematologic toxicity. 
No objective response was achieved, and the performance status decreased from 0 to 2 , with a 7-kg weight loss.

After 5 months of sorafenib therapy, an MRI revealed further progression at all sites (fig. 1 ; online suppl. video 1; see www.karger.com/doi/10.1159/000323804). At the end of August 2009, temsirolimus was started as a third-line treatment at a dose of $25 \mathrm{mg}$ intravenously every week. In November 2009, disease stabilization was observed on CT. In February 2009, a further MRI showed a partial remission according to the RECIST criteria. Clinically, the patient had improved considerably (PS 0), and formerly elevated laboratory values normalized (LDH from 1,400 U/l, alkaline phosphatase from $142 \mathrm{U} / \mathrm{l}, \gamma \mathrm{GT}$ from $168 \mathrm{U} / \mathrm{l})$.

In July 2010, an impressive partial remission was documented by MRI (fig. 2; online suppl. video 2). Currently, the patient continues on weekly temsirolimus, is working full time, and is in excellent physical condition without experiencing any side effects.

\section{Discussion}

This clinical observation of an impressive response to third-line temsirolimus in a case of chromophobe metastatic RCC leads us to raise the following questions: first, should the current practice of sequential therapy be revisited? Especially in chromophobe metastatic RCC, mTOR inhibition may be considered earlier. In this patient, the treatment choice was dictated by availability. Today, everolimus is the standard in second-line treatment [1], while temsirolimus is approved only for first-line treatment [2]. Thus, temsirolimus in later lines is still considered experimental.

Second, are all mTOR inhibitors equal in terms of efficacy? Would this patient have responded equally well to everolimus? This question should be addressed by head-to-head comparisons of mTOR inhibitors.

Since 2006, six molecular targeted agents have been approved for the treatment of RCC (sunitinib, sorafenib, bevacizumab/interferon, temsirolimus, everolimus, and pazopanib). Currently, sequencing of these agents is based mainly on prognostic risk scores. Maybe more emphasis should be placed on the biology of RCC as reflected in its histology. Rare subtypes like chromophobe RCC or sarcomatoid dedifferentiated RCC may have to be considered separately. Current strategies are based on results obtained in the context of clear cell-type RCC. Separate trials for rare histologies seem unfeasible and are unlikely to be performed. For these cases, clinical observations are an important part for advancing therapeutic insight.

Currently, the 'START' trial [3] is studying temsirolimus as first-line and second-line treatment. Patients in this trial are stratified by histological subtype, and the results may also answer the question raised by our observation: is chromophobe RCC particularly sensitive to mTOR inhibition? 


\begin{tabular}{r|l|l|l}
$\begin{array}{c}\text { Case Reports in } \\
\text { OlColoyy }\end{array}$ & $\begin{array}{l}\text { Case Rep Oncol 2011;4:16-18 } \\
\text { DOI: } 10.1159 / 000323804\end{array}$ & $\begin{array}{l}\text { Published online: } \\
\text { January 15, 2011 }\end{array}$ & $\begin{array}{l}\text { ( 2011 S. Karger AG, Basel } \\
\text { ISSN 1662-6575 } \\
\text { www.karger.com/cro }\end{array}$ \\
\hline
\end{tabular}
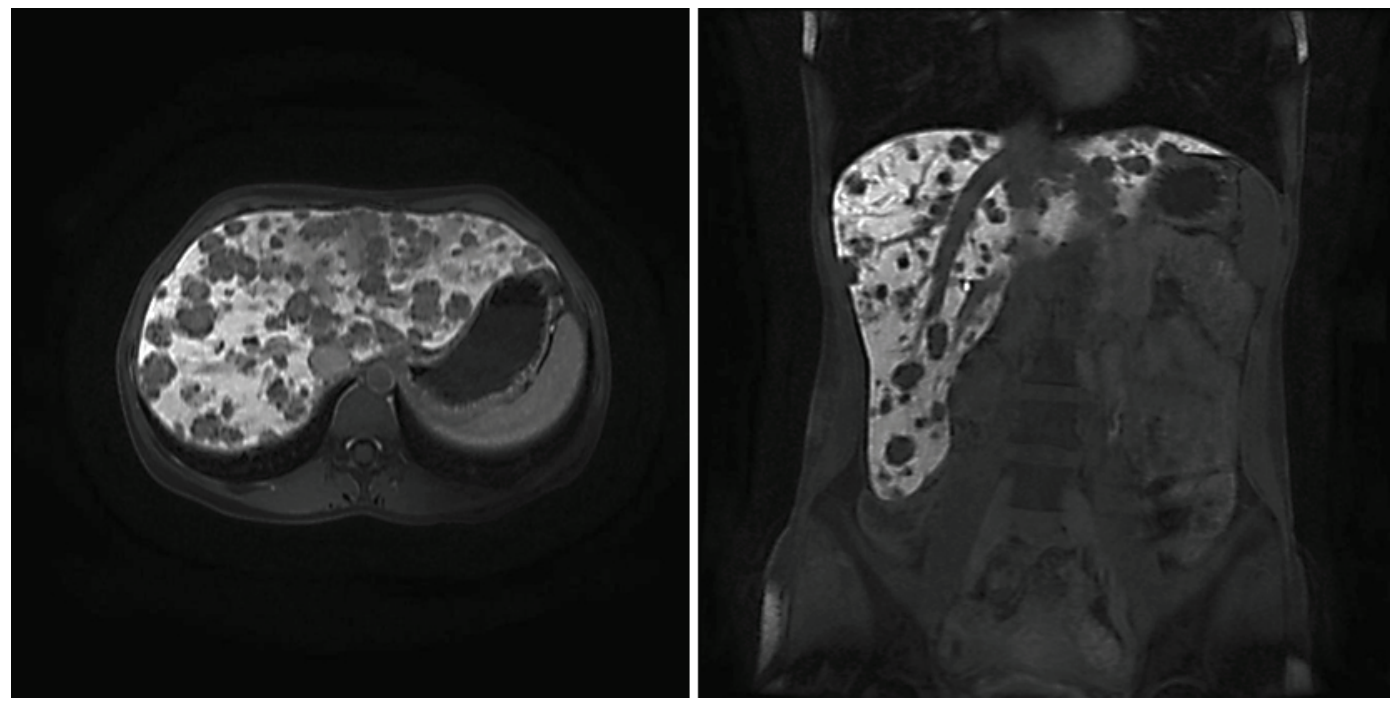

Fig. 1. MRI after sunitinib and sorafenib failure.
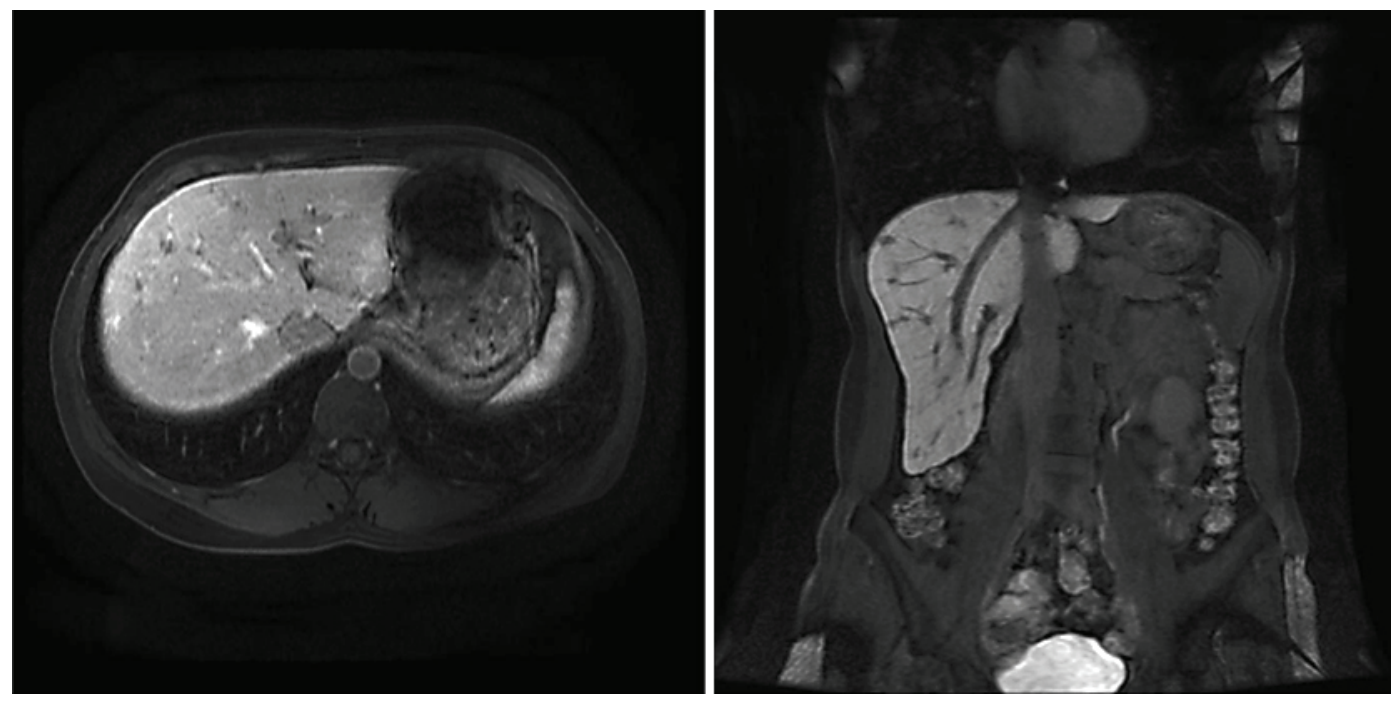

Fig. 2. Partial remission after 9 months on temsirolimus.

\section{References}

1 Hudes G, Carducci M, Tomczak P, Dutcher J, Figlin R, Kapoor A, Staroslawska E, Sosman J, McDermott D, Bodrogi I, Kovacevic Z, Lesovoy V, Schmidt-Wolf IG, Barbarash O, Gokmen E, O’Toole T, Lustgarten S, Moore L, Motzer RJ, Global ARCC Trial: Temsirolimus, interferon alfa, or both for advanced renal-cell carcinoma. N Engl J Med 2007;356:2271-2281.

2 Motzer RJ, Escudier B, Oudard S, et al: Efficacy of everolimus in advanced renal cell carcinoma: a double-blind, randomised, placebo-controlled phase III trial. Lancet 2008;372:449-456.

3 START 'Sequential Two-agent Assessment in Renal Cell Carcinoma Therapy'. ClinicalTrials.gov Identifier: NCT01217931. 